\title{
Nosso encontro com a leitura e a ALB: memórias e sentidos
}

\section{Our encounter with reading and ALB: memories and meanings}

https://doi.org/10.34112/2317-0972a2020v38n79p113-120

Rute Batista de Pontes ${ }^{1}$

O TEXTO, EM SEQUÊNCIA, ESTÁ NA SUA ESSÊNCIA, FIEL À NOSSA FALA durante a realização da Mesa-Redonda com os ex-presidentes da ALB na noite de 17 de junho de 2017, no $18^{\circ}$ Congresso de leitura do Brasil. Como é natural, na ocasião entremeamos sua leitura com comentários e esclarecimentos e deixamos de seguir, ipsis litteris, alguns parágrafos o quê, de modo algum, compromete o que ora damos a conhecer. A necessidade deste esclarecimento deve-se ao fato de a Mesa-Redonda ter sido transmitida via Internet, em tempo real.

Ao refletirmos sobre as comemorações dos 30 Anos da ALB e a diversidade de sentidos contida na ousada e desafiadora travessia desta respeitada entidade, buscamos neste momento, verbalizar a expressão do nosso sentimento, da nossa fala interna e entrelaçá-los com esses sentidos. Pensamos, então, a partir deste depoimento pessoal, reconstruir essa trama, cujos primeiros fios, começaram a tomar corpo em 1991; ano do nosso ingresso no Mestrado em Biblioteconomia, na Pontifícia Universidade Católica de Campinas-PUCCAMP. Época, que significou adentrar um novo caminho, enfrentar os percalços próprios de quem prefere ser uma protagonista da cena social e, não apenas, expectadora desta. Nossa intenção,

1. Docente do Departamento de Ciências da Informação, Curso de Biblioteconomia - Universidade Federal do Ceará. Atuou como Presidente da Associação de Leitura do Brasil-ALB - 1992-1993. 
então, era aprofundar informações e conhecimentos no campo da Administração Científica, área na qual trabalhávamos, como bibliotecária, na condição de diretora da Biblioteca Central da Universidade Estadual do Ceará. Embora, também, pudéssemos nos realizar na área de conhecimento, aludida, sentimos que era a oportunidade de mudar o curso profissional.

Conscientes de que, para abraçar a Leitura seriam necessários alguns tombos, mas com a certeza de estar diante de uma nova e fascinante missão decidimos, dali para frente, acrescentar ao nosso fazer profissional, social e pessoal conhecimentos que nos ensejassem seguir na direção desse universo, que se nos afigurava como pleno de possibilidades. Atendíamos, pois, a um chamado latente no nosso ser esperando apenas, o momento e o lugar certos, para nos entregarmos a essa nova construção. Logo, essa certeza concretizou-se através de oportunidades que nos permitiram ser mais; de poder compartilhar com o Outro, tanto o aprendizado quanto as experiências advindas das interações, diálogos e trocas vivenciadas nesse momento de aprimoramento da nossa formação acadêmica. De outro modo, o desejo de ir traçando as possíveis formas de atuação no nosso solo natal, tão prenhe de dificuldades de toda ordem.

Embora, a leitura não seja a solução para todos os males que afligem o ser humano, concordamos com o que pontua Michèle Petit, no seu mais recente livro $A$ Arte de Ler; ou como Resistir à Adversidade, a leitura é um

[...] instrumento privilegiado para a reconstrução [...] de identidades e histórias pessoais. [...] uma reserva de liberdade necessária, um espaço de devaneio fundamental para a recomposição do tecido simbólico esgarçado por catástrofes, sejam elas externas ou internas.

Ou seja, constitui-se em um dos veios para conduzir com equilíbrio a nossa existência. Isto, realça com muita clareza as condições de vida do contexto nordestino e acentua que a leitura contribui, em muito, para resistir aos embates que lhe são impostos.

Retomando, um pouco, a nossa fala anterior o quê, de início, marcou profundamente a nossa curiosidade intelectual, ao primeiro contato com a disciplina, "Processos de Leitura", ministrada pelo Prof. Ezequiel Theodoro, no Mestrado, foi o entendimento de que os conteúdos da mesma, e a forma como eram trabalhados em sala de aula, na realidade, alertavam para dar vida ao nosso próprio grito; para a voz interna que passava a compreensão de que, deveríamos escutar, de modo 
atento e presente a esse grito, na esperança de contribuir de forma mais efetiva para um mundo melhor.

Esclarecemos que, a integralização curricular do Curso de Biblioteconomia, da Universidade Federal do Ceará, na ocasião, não contemplava nenhuma disciplina voltada para a teoria e prática da leitura. O Curso, predominantemente, tecnicista nos formava para organização e tratamento das materialidades documentais gráficas - impressas - na sua maior parte; com ênfase para o livro. Essa formação continua sendo fundamental, ainda, hoje. Mas, sentíamos que faltava algo e, esse algo veio à lume durante o desenrolar da disciplina "Processos de Leitura." Encantou-nos, descobrir a leitura como área de conhecimento a ser explorada em uma diversidade de formas, jamais pensada por nós.

Acrescido ao encantamento dessa descoberta a participação, como ouvinte, do $8^{\circ}$ Congresso de Leitura do Brasil ( $\left.8^{\circ} \mathrm{COLE}\right)$ no mesmo ano. Colocando-nos, sempre, na condição de aprendiz fomos galgando os primeiros passos, cercadas de esperança e muitos sonhos.

No ano seguinte - 1992 - a ALB deveria dar continuidade às suas ações, através de uma nova Diretoria. Atendendo ao convite do Prof. Ezequiel, nós, e, mais, Beteizabete de Brito, da Universidade Federal do Rio Grande do Norte, nesse momento, cursando doutorado no Instituto de Estudos da Linguagem-IEL - já falecida; César Castro, da Universidade Federal do Maranhão, também aluno do Mestrado da PUCCAMP, a pedagoga Marlene Ramos, professora da rede pública de ensino local, Maria Lucia, também de Campinas, dentre outros, formamos um grupo para compor a nova chapa e submetê-la à aprovação dos seus associados. Realizada a eleição, movidos por um forte compromisso político e uma enorme vontade de acertar assumimos a ALB, nesse período. Por primeiro, como VicePresidente e, em decorrência da renúncia do Prof. Eduardo Andrade, eleito presidente, assumimos, após curto período do seu mandato, a Presidência. Diante do respeito que esta entidade conquistou, junto a educadores, bibliotecários, agentes culturais, tanto em nível local como nacional; enfim, todos quantos de uma forma, ou outra, sentem-se responsáveis pela causa da leitura no País, com certeza, teríamos pela frente um complexo fazer, mas, não impossível de ser concretizado.

Assim, a gestão da Associação de Leitura do Brasil durante o exercício 1992-1993, resultou dessas leituras, desses sentidos, palavras, gritos e gestos que nos inundaram, por completo. Sempre que necessário, buscávamos dirimir nossas dúvidas junto ao Prof. Ezequiel. A segurança e a liberdade de ação chegaram à medida que 
refletíamos sobre os fazeres e as responsabilidades diante de nós, e os meios mais eficazes de como lidar com cada situação que se nos apresentava. Estávamos sempre alertas ao chão que pisávamos, a nós mesmos. Observação, percepção e escuta sensível, foram instrumentos imprescindíveis a nos guiar para a apreensão não só de gritos explícitos, mas, daqueles que vieram à tona por meio de silêncios.

Em 1993, presidimos o $9^{\circ}$ Congresso de Leitura do Brasil. Logo a seguir, a ALB recebeu da Câmara Brasileira do Livro, uma homenagem durante a realização da Bienal Internacional do Livro do Rio de Janeiro, como reconhecimento à sua inestimável atuação na democratização do acesso à leitura no País. Participamos, também, da Bienal Internacional do Livro de São Paulo, com stand próprio. Para a concretização dessa ideia, contamos com o concurso de José Mindlin, eminente bibliófilo (já falecido) que se considerava [...] um leitor incansável e, o que é mais grave, um leitor indisciplinado [...] por ler quase tudo que lhe caía nas mãos, segundo afirma no seu livro de memórias - Uma Vida Entre Livros: Reencontros com o Tempo - Mindlin, de imediato, enviou-nos generoso recurso financeiro. Registramos, também, o valioso apoio da Faculdade de Educação (FE) da UNICAMP com a infraestrutura material necessária para a montagem do stand. E, assim, com entusiasmo e espírito de luta, enfrentamos tudo o que um empreendimento dessa natureza comporta, em termos de desafios, até o final da nossa gestão.

Com a leveza da consciência de quem tem a convicção do dever cumprido e internalizando o sentimento do privilégio de sermos parte da história da Associação de Leitura do Brasil, retornamos ao nosso lugar de origem, tão logo concluímos, também, nossas pós-graduações. Na memória, espaços de tempo que permanecem indeléveis dentro de cada um(a) que compôs a Diretoria - 1992-1993, temos certeza.

A ALB, após 30 anos de existência, se fortalece, cada vez mais; agiganta-se. Isto, quer dizer, confiança que gera entrega; entrega, com a convicção de que é possível uma nova práxis para a Educação e a Cultura brasileiras. Cremos na missão, da ALB, sobremaneira, como uma missão de cuidado com o Outro. Leitura é, também, ato de cuidar, atento à condição humana; à complexidade de que se reveste.

Entrelaçar, pois, a nossa formação em leitura, a partir da segura orientação do Prof. Ezequiel Theodoro e o exercício da presidência da ALB, é tecer uma trama de relações de sentidos que, dentro do espírito do tempo que estamos a viver, com tantas contradições, inquietações, dúvidas e medo, está a clamar por respostas, pelo direito de viver com dignidade, respeito, equanimidade. Ler, nessas circunstâncias, torna-se uma busca constante, um preparar-se para a adversidade, lembrando, mais uma vez, Michèle Petit. 
Confirmamos, pois, o compromisso de seguir na busca por ser mais; ser mais, no sentido do domínio da competência informacional e conhecimento necessários, alinhando-os à sabedoria, ao discernimento. Sem sabedoria e sem discernimento, informação e conhecimento têm aplicação desviada da sua verdadeira finalidade: o bem-estar e a felicidade humanos.

Desse modo, insistimos na luta pela conquista de uma educação de qualidade. $\mathrm{Ou}$ seja, nas reivindicações, estratégias de ação, no escutar das vozes que se levantam contra esse caótico quadro da formação humana, temos um propósito em comum: remover a barreira que facilita o acesso à Escola sem recursos político-pedagógicos que garantam a permanência do aluno no ambiente escolar, afastando o fantasma da evasão, em alta, sempre. Docentes, em geral, desrespeitados nos seus mais inalienáveis direitos.

Deparamo-nos com essa vergonhosa realidade, cuja fisionomia apresenta-se, cada vez mais cruel, também, na forma do analfabetismo funcional, cujos tentáculos, estão presos a problemas que compõem o leque de necessidades humanas básicas. Estas, a merecer urgentes providências, mas, vistas como se, assim, não fosse. Como os indicadores de ordem quantitativa são exaltados a todo momento, a população mais atingida, desprovida de consciência crítica, continua a acreditar que tudo está muito melhor. Esses, a mascarar um contexto que está distante de alcançar parâmetros de qualidade. Exceção aos casos que se constituem como ilhas de competência, principalmente, na rede escolar privada.

Não radicalizando essa questão, a Escola galgou passos importantes, mas, é patente o agravamento dos problemas, especificamente, do saber ler e escrever; expressões estas, consideradas no que comportam de mais profundo e abrangente. Tampouco, estamos a negar as políticas públicas governamentais, educacionais e culturais que, do ano 2000 para cá, vêm despendendo esforços na intenção de mudar essa distorcida face que se acerca da tríade: leitura, livro e biblioteca. Entretanto, acentuamos, ainda, não encontraram o seu norte.

Cremos numa política de Estado que contemple todos os setores de atividades humanas, tendo no topo das suas prioridades a Educação. Não é novidade afirmarmos que um país só se faz respeitar diante da sua sociedade e, do contexto internacional, se a educação do seu povo se alicerçar em bases sólidas e solidárias. A situação como está, é como diz Leonardo Boff, no livro Sustentabilidade: o que é - o que não é: continuarão [...] os gritos lancinantes de famélicos e miseráveis [a elevar-se ao céu; ] poucos os que ouvem os seus lamentos. 
As atuais políticas governamentais têm uma visão míope com relação a empreendimentos educacionais e culturais já consolidados, apresentando promissores resultados. Alguns programas de incentivo à leitura sofreram interrupções ou foram ameaçados de extinção. Mencionamos, como exemplo, o Agentes de Leitura, no Ceará, voltado para cidades onde o Índice de Desenvolvimento Humano-IDH, abaixo da linha de pobreza, estava a exigir providências urgentes, afetas à questão do desempenho em leitura e escrita. No período de transição de um governo para o outro, não faz muito tempo, esse programa passou, praticamente, um ano, para ser retomado. Lembramo-nos, bem, das fisionomias daquelas pessoas, ávidas por aprender, do município de Nova Olinda, sul do Estado, ao chegarmos para dar continuidade à formação dos selecionados para prepararem-se como agentes de leitura. Um deles adiantou-se, ansioso e, disse: Professora, faz um ano que a gente espera pela senhora; já não 'tinha' mais esperança de você estar aqui.

Hoje, esse programa concebido e desenvolvido pelo Dr. Fabiano dos Santos, através da Secretaria de Estado da Cultura do Ceará, enfim, tem o respeito e o reconhecimento do Governo Federal, e desenvolve-se através do Ministério da Cultura., embora, ainda, prescinda de olhares mais presentes e escutas mais atentas, por parte de quem, atualmente, o dirige.

Inúmeros são os contornos dos gritos advindos da nossa escuta atenta: cenas como esta que passarei a narrar são mais comuns e constantes do que pensamos: ontem, ao chegarmos a Campinas, ligamos para uma amiga, ex-colega de mestrado. Ao querermos deixar um recado, a senhora que nos atendeu, falou: moça, não adianta deixar recado; não sei ler, nem escrever; sou faxineira. Na sua forma ingênua de pensar, faxineira não precisa saber ler e escrever.

Um outro momento, que sentimos como um grito no silêncio da madrugada, deu-se à nossa frente, ao regressarmos à casa, em Fortaleza: um homem cuja aparência revelava o seu estado de carência física, espiritual e emocional, pelo rigor da sua lida - Catador de Lixo - conduzia sua carroça, abarrotada de lixo reciclável, por ele mesmo puxada. Cobria o produto do seu trabalho, uma imensa bandeira do Brasil. Bem visível: Ordem e Progresso. Quanta contradição! Que ordem é essa, que progresso é esse que impõem ao ser humano tanta desumanização, tão precárias condições de vida? Precisamos, sim, de uma nova ordem política, social, econômica e, essencialmente, humana. 
O tema do $18^{\circ} \mathrm{COLE}$, espelha, com muita propriedade, os gritos e os clamores que testemunhamos, no cotidiano, quaisquer que sejam o lugar e a hora: $\mathrm{O}$ MUNDO GRITA. ESCUTA?

Em que pese todas as ações concretizadas, ainda temos um longo percurso pela frente. Assim, como isto continua a nos inquietar, a nos afligir, também nos impulsiona a enfrentar as procelas, em alto mar, na busca por um porto seguro onde possamos ancorar a nossa embarcação e cumprir a nossa missão. Missão entremeada de denúncias e anúncios de novos desafios. O conhecimento a partir do qual temos pautado a nossa conduta, como formadora de leitores é um conhecimento que sempre tem o Homem como meta, respeitando as suas potencialidades e buscando superar as suas limitações.

Na nossa fala, contemplamos ideias e pensamentos já expressos, não só neste evento, é verdade. Mas, isto, é uma confirmação da sintonia do nosso compromisso; insistimos em alcançar o mesmo alvo: um Brasil cujo equilíbrio repouse no desenvolvimento sustentável; na conquista da humanização dos seus filhos, como requisito fundamental para o exercício da cidadania na sua inteireza. Enfim, um Brasil leitor.

Antes de concluirmos, gostaríamos de dizer que, após abraçar a docência, em 1999, assumimos a coordenação do comitê do Programa Nacional de Incentivo à Leitura (PROLER), em Fortaleza. Aqui presente, a Professora Elizabete Serra que, nesse ano, integrava a equipe que dirigia o PROLER Nacional, quando tivemos a oportunidade de, na reunião anual de avaliação do Programa, melhor conhecê-lo e dar continuidade às suas ações.

No Brasil, o PROLER está a completar 20 anos de profícua atuação; na Universidade Federal do Ceará, desenvolve-se como uma ação de Extensão, há 17 anos. Sob a nossa coordenação, há 13. Impressiona-nos a força e a coragem dos diversos coordenadores de comitês que integram o Programa por este país afora, mesmo diante de obstáculos quase intransponíveis. Seguem em frente ignorando as pedras no caminho e, assim, conferindo mais credibilidade e reconhecimento ao que foi o primeiro programa, no Brasil, com fisionomia de política pública, centrada no livro, leitura e biblioteca.

Obrigada, pela delicadeza da atenção de todos(as); à Prof a Lilian, coordenadora do Projeto 30 Anos-ALB; ao Prof. Antonio Carlos, atual presidente da ALB. Um agradecimento especial ao mestre, Prof. Ezequiel Theodoro, que naquele já distante $8^{\circ}$ COLE, em 1991, ao lançar o livro De Olhos Abertos: Reflexões Sobre o Desenvolvimento da Leitura no Brasil, fez, para nós, a seguinte dedicatória: Rute, é certo que já somos amigos. O Livro faz isso. Aqui, estamos para confirmar as palavras 
Nosso encontro com a leitura e a ALB: memórias e sentidos

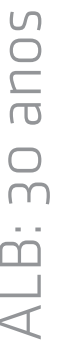

do Prof. Ezequiel. Não importam o tempo e a distância. Mas, sim, a união pelos mesmos ideais e propósitos. 